\title{
Discussion on Integrating Ideological and Political Education into Dance Classroom of Preschool Education Specialty in Colleges and Universities
}

\author{
Yan Jing ${ }^{1, a}$, Fu Fang-yi ${ }^{1, b}$, Bi Zhi-li ${ }^{2, c^{*}}$ \\ ${ }^{1}$ College of Education, Binzhou Polytechnic, Binzhou, Shandong, China \\ 2 Academy of health, Binzhou Polytechnic, Binzhou, Shandong, China \\ a122512401@qq.com \\ b274927362@qq.com \\ c*beelili@126.com
}

\begin{abstract}
Ideological and moral conduct has always been one of the most valued talents of the Chinese nation, and it is also regarded as the most important teaching content in basic education. Especially for the talent cultivation of preschool education majors, only by improving their ideological and political accomplishment can they provide strong support for the transmission of correct values to students in the future education work. Based on this, this paper takes the dance classroom teaching of preschool education major in colleges and universities as an example, analyzes how to integrate ideological and political education and puts forward some suggestions, hoping to bring new help to the development of related work.
\end{abstract}

Keywords: College teaching, preschool education major, dance class, ideological and political education, fusion analysis

\section{高校学前教育专业舞蹈课堂融入思政教育的探讨}

司晶 ${ }^{1, \mathrm{a}}{\text { 傅方一 }{ }^{1, \mathrm{~b}} \text { 毕智丽 }}^{2, \mathrm{c} *}$

1 滨州职业学院教育学院, 滨州, 山东, 中国

2 滨州职业学院健康学院, 滨州, 山东, 中国

122512401@qq.com

b274927362@qq.com

c*beelili@126.com

\section{摘要}

思想品行一直以来都是中华民族最为看重的人才素养之一，基础教育也将其视为了最重要的教学内容。尤其是 对于学前教育专业的人才培养来说, 只有提高了他们的思政素养, 才能为其在未来教育工作中向学生传递正确 的价值观念提供有力支持。文章立足于此, 以高校学前教育专业的舞蹈课堂教学为例, 对如何融入思政教育展 开了分析并提出了一些建议, 希望能够为相关工作的开展带来新的帮助。

关键词: 高校教学，学前教育专业，舞蹈课堂，思政教育，融合分析

作者简介: 间晶 (1990-), 女, 山东博兴人, 讲师。国家三级心理咨询师, 研究方向为职业教育、舞蹈教学、 课程思政。 


\section{1. 引言}

近些年来，伴随社会经济条件的提升和总体环境 的变化, 人们对物质层面的需要越来越容易得到满足, 而对精神层面的需要就显得越来越高, 逐渐成为生活 中更迫切需要得到满足与提升的主要矛盾。因此, 艺 术类学习越来越得到了更多重视, 幼儿教育随之开始 越来越多地融入音乐、舞蹈、美术等艺术类内容。在 此环境下, 高校学前教育专业开始设置舞蹈等专业课 程, 旨在通过培养具有良好舞蹈素养的高校学前教育 专业学生, 为他们在后续的职业发展中, 进行幼儿全 面教育工作的落实做好铺垫。为了更好地提高高校学 前教育专业人才培养的质量, 达到使学生全面发展的 育人目标, 在相关课程的教学过程中, 融入思政元素 开展教育是必不可少的。

\section{2. 思政教育融入高校学前教育专业舞蹈课程 的重要价值}

在高校学前教育专业舞蹈课程的授课过程中, 将 思政元素以丰富多彩的操作形式, 于潜移默化之中进 行融入, 不但可以使高校学前教育专业的学生们在思 政素养方面得到提升, 还可以在以下两个方面体现这 种融合的价值:

\section{1 迎合社会发展和课程改革需要}

2019 年 3 月,在思想政治理论课教师座谈会中, 习近平总书记曾指出: “落实立德树人根本任务, 需 以思想政治理论课为支持”。与此同时, 新课改也对 思想政治理论课与其他科目的融合教学进行了强调, 认为需要在各个科目中融入思政元素, 全员育人, 使 得学生的道德素养可以持续得到培养。因此, 我们有 理由认为, 高校学前教育专业开设的舞蹈课程与思想 政治教育的融合, 是迎合社会发展与课程改革需要的 必要手段, 是高校学前教育专业实现 “育人” 这一教 育目标的必经之路, 也是高校学前教育专业学生在日 后个人的职业发展过程中, 为幼儿成长和社会人才培 养做出贡献的必然需要 ${ }^{[1]}$ 。

\section{2 促进教师与学生专业素养发展}

其次, 思政教育融入高校学前教育专业舞蹈课程 能够促进任课教师个人能力与学生基础素质、核心能 力、专业素养等方面的协同发展。简单来说, 教师在 舞蹈课程中融入思政知识的过程, 本质上也是一个学 习相关内容的过程, 这必然能够促进教师个人政治素 养和专业教学能力的发展。而一旦教师教学能力得到 提升, 他们必然可以更好地扮演 “知识传播者” 和 “学 生行为引导者” 的角色, 将思政知识借助学科课程以 更加合适的手段讲授给学生。这样一来, 学生得到了 正确引导, 其道德素养也必然会伴随专业能力的提升 而得到提高。

\section{3. 高校学前教育专业舞蹈课堂融入思政内容 的现实阻碍}

将思政元素融入高校学前教育专业舞蹈课程的 价值实现具体路径的探索过程中, 因为有新内容的选 择、新方法的实践、新角色的体验等创新工作, 而创 新需要试错的过程, 这就必然使教师、课程、学生三 方面都产生一定的阻碍作用。

\section{1 教师能力方面}

对当前高校学前教育专业舞蹈课程中思政元素 融入教学的现实情况进行梳理和分析, 可以发现, 最 突出的阻碍来自于教师缺乏良好的创新意识和融合 教学能力。从教师的角度来说, 部分年龄偏大、教龄 较长的教师, 或受传统教育理念影响严重, 存在 “思 想局限” 类的问题, 或拘泥于个人已有的教学经验和 熟练的教学手法, 都更加关注对于 “舞” 的技巧的讲 解与演示; 而很多年轻教师又因为缺乏教学经验, 更 关注 “备” 专业内容, 无㗇关注 “备” 学生的进阶需 要。这都使得任课教师对学生思想政治意识发展缺乏 关注, 严重制约了教师们对于思政教育元素与学科课 程内容的融合设计 ${ }^{[2]}$ 。

\section{2 课程本质方面}

对当前高校学前教育专业舞蹈课程中思政元素 融入教学的另一个突出的阻碍, 是这类课程本身原有 的架构设计得不甚合理，尤其不适合直接与思政元素 的融合。从课程角度来说, 舞蹈课程中的思政元素挖 掘是一个非常繁琐的过程, 也是一个创新的过程, 需 要任课教师非常耐心细致地工作。而大多数高校学前 教育专业的舞蹈教师, 在该方面都缺乏足够的经验, 也缺乏必备的技能，这必然会影响 “融入” 目标的实 现。

\section{3 学生个人选择方面}

对当前高校学前教育专业舞蹈课程中思政元素 融入教学, 在学生个人选择的方面, 也存在着一定阻 碍。思想政治教学原本就是理论性较强的一项教学活 动, 学生极易对其产生枯燥、乏味之感, 甚至出现一 听到老师讲道理就生出逆反心理的现象, 加之舞蹈训 练本身的动态感更强, 往往更能吸引学生注意力, 动 作的过程产生的愉悦情绪更促进学生采取肢体表达, 这均阻碍了学生对于 “融合教学” 的参与, 影响了他 们在该学科课堂中对于思政内容的学习和内化。甚至 一些学生由于刚刚脱离高中生活, 会在思想与行为方 面出现严重的 “解怠” 表现, 这也是构成整体教学效 果差强人意的重要原因。 


\section{4. 思政教育融入高校学前教育专业舞蹈课程 的具体策略}

在充分分析了高校学前教育专业舞蹈课程融入 思政教育元素的现实阻碍因素基础上, 为最大可能实 现其价值, 需要采取以下策略来克服以上三方面的阻 碍作用:

\section{1 结合专业内容, 挖掘思政元素}

首先, 就是要围绕高校学前教育专业的人才培养 方案和相关课程标准, 积极挖掘舞蹈课程的思政学习 元素。简单来说, 高校学前教育专业的舞蹈课程, 其 核心教育目标是培养学生的舞蹈素养和能力、编舞理 论和技能, 为将来其进行学前幼儿的教育教学打好基 础。因此, 即便是融入思政元素, 也要保证基础舞蹈 课程内容本身的有序推进和作用发挥。

也就是说, 在 “融入”之前, 任课教师一定要对 “舞” 的背后所蕴含的思政元素展开细致分析。例如, 古典舞、民族舞、民间舞不约而同地都是对民族舞蹈 文化的一种传承, 是对艺术文化的创新和弘扬, 这就 是思想政治教学的可依托对象。此时, 任课教师就可 以从中挖掘思政教育元素, 例如, 某种民族舞蕴含了 该民族哪种独一无二的文化现象, 某种民间舞表达了 对哪一民俗的传承等。这样一来, 学生探索 “舞” 的 世界的过程, 也就是一个钻研博大精深的文化内涵的 过程, 其文化意识、文学素养均能得到一定程度的提 升。而这一提升, 还可以让他们带着对文化的热爱, 更加主动地参与到后续相关舞蹈学习活动中, 进一步 促进学生对课程学习兴趣的提升与将思政内容内化 于心、外化于下等良性循环的形成。

\section{2 围绕红色精神，丰富融合教学}

其次, 就是可以将 “井冈山精神” “长征精神” “延安精神” “红船精神” “抗战精神” “老渤海精神” 等 “红色精神”, 融入到高校学前教育专业的舞蹈课 程中去。一直以来, “红色教育” 都是我国在党的领 导下的教育体系中重点关注的内容, 其目的就在于培 养学生的爱国意识和社会责任感。同样, 这一教育内 容需要从娃娃抓起。也就是说, 高校学前教育专业的 学生在投入幼儿学前教育工作后, 也要向学生传递 “红色精神”。

因此, 无论是从丰富高校舞蹈教学的角度出发, 还是站在为其后续通过 “舞” 的教学向幼儿传递正确 的家国意识的立场上, 教师都可以将 “红色精神” 融 入到舞蹈教学工作实践中 ${ }^{[3]}$ 。例如, 在民族民间舞的 “藏族舞” 相关课程活动中, 教师就可以将 “藏族人 民在中华民族过往革命工作中的突出贡献”, 借助舞 蹈教学传授给学生, 也可以结合藏族人民的革命真实 事件, 编排意义深远、形式特别的新舞。如此一来, 学生无论是在学习中, 还是在演绎舞的过程中, 都将 是一个感受 “红色精神” 的过程, 其家国信仰都能够
在 “舞” 的学习中变得更加坚定, 也必然可以在日后 将 “红色精神” 通过舞蹈教学更好地向学前幼儿们传 递下去。

\section{3 科学利用媒体, 促进思政融合}

再者, 信息时代通讯工具的不断发展, 为社会生 活带来了巨大的变化和强烈的冲击, 也促进了原有教 育教学结构的改革, 为教师教学与学生学习带来了新 的选择。高校学前教育专业舞蹈课程的任课教师们, 在设计思政融合教学活动时, 还可以适当将信息技术 和多媒体工具充分利用起来, 以便设计出更加生动、 活泼的教学活动, 将思政元素通过动态的舞蹈情境进 行展示, 或为 “融合教学” 创建一个特定的背景, 增 强学生学习的外界支持 ${ }^{[4]}$ 。例如, 在 “维吾尔族舞” 课程活动中, 教师就可以先上网搜索有价值的维吾尔 族舞视频, 分析其中蕴藏的思政元素, 并将其在课堂 上借助多媒体进行展示, 改变“直接演绎舞”的形式, 避免因自己的技巧动作不规范使学生对 “舞” 的思政 内涵造成错误认识。

\section{4 加强内部合作，实现特色教研}

另外, 还要加强内部合作、促进特色教研工作的 推进, 以特色教研活动, 为舞蹈课程与思政元素的融 合创造更多支持。简单来说，思政元素的教学活动与 高校学前教育专业舞蹈课程的融合, 不仅是舞蹈教师 自身要承担的责任, 也与人文社科等其他课程的任课 教师有着密不可分的联系。因此, 舞蹈课程教师应适 当与其他课程教师建立合作关系，与之共同挖掘、探 讨舞蹈课程中的思政元素, 并合作设计丰富多彩的相 关教学活动 ${ }^{[5]}$ 。例如, 在 “古典舞基训” 课程的教学 实践活动中, 舞蹈教师可以与历史、美术、思政等学 科的任课教师合作，由历史老师挖掘古典舞对应的历 史知识, 由美术老师挖掘古典舞特色服装背后蕴藏的 文化内涵, 由思政老师把关大家挖掘出的教育素材如 何有效地与舞蹈教学和思政元素进行融合。进而在各 科教师的通力协作、教研帮助下, 将挖掘到的人文历 史、服装文化等隐性融入民族自信心与自豪感、爱国 情感、美感等思政元素, 并与基础舞技法的教学巧妙 结合起来, 促使学生对 “舞” 的背后思政内容进行深 度理解与学习。

\section{5 注意实践引导, 多元组织学习}

“实践出真知”，对舞蹈这样特别注重实践能力 的课程尤其适用, 舞蹈课程中融入的思政元素, 也会 随着学生对舞蹈技能的掌握, 而被一起掌握。因此, 舞蹈课任课教师应多为学生提供实践机会, 同时鼓励 学生积极主动把握这些机会, 通过实践将所学更好地 掌握并内化。 


\section{5.1 登台表演}

高校学前教育专业学生对于舞蹈课程的学习, 不 仅仅是为了理解舞蹈理论技巧, 更是要提升自身设计 并演绎舞的能力, 为之后的学前幼儿教育工作打基础、 做准备。因此, 教师应鼓励学生多参加各种实践活动, 让他们结合自身对所学舞蹈内容和思政元素的理解, 自行编排舞蹈, 并为其提供登台表演的机会。例如, 在 “幼儿舞蹈创编” 课程活动中, 任课教师就可以通 过组织演出活动, 要求学生自行编舞并进行表演, 让 他们在编排和演绎的过程中, 加强对思政知识的学习, 进一步提高其在 “舞” 中传递正确价值文化理念的能 力与意愿。

\section{5.2 社会活动}

此外, 任课教师还可以通过组织社会活动的方法, 使学生能够将舞蹈课上的学习收获, 在实践活动中发 挥价值。如同陶行知先生所言: “社会即学校, 生活 即教育”, 引导学生在社会活动中学习并应用 “舞” 的知识, 可以在无形中拉近他们与社会思政的距离, 为其学习更加实用的思政知识、编排更能够反映社会 现实和发展需要的舞, 提供有效帮助。因此, 在 “幼 儿舞蹈创编” 课程活动中, 教师还可以将学生带出校 园, 鼓励他们到幼儿园或学前、早教等机构中表演自 己编排的舞, 以“义演”、“义务教学” 等方式, 一边 培养学生的实践教学能力, 一边深化其思政意识。尤 其是这一过程还能让学生提前感受到幼儿舞蹈教学 的独特鬼力, 对其职业责任感的建立和职业认同感的 提升都大有帮助。

\section{5. 结束语}

综上所述, 高校学前教育专业的舞蹈课是一类综 合性较强的专业技能课程, 对其融合思政元素进行教 学, 往往更能提高教育质量, 促进学生专业素养的积 极发展, 为其日后在幼儿教育教学工作中更高质量地 讲授 “舞” 的知识提供帮助。高校学前教育专业舞蹈 课任课教师应对此形成正确认识, 积极在舞蹈课程中 寻找思政教学元素, 并用灵活多样的方法在教学过程 中传递给学生, 同步培养其基础舞能力和思政素养, 以促使学生专业得到更好的发展, 并助力学前教育事
业的健康发展。

\section{项目基金}

本文为以下基金项目的阶段性成果： 1 . 滨州市 2022 年度社会科学规划课题职业教育 研究专项《高职学生规则意识的培育研究》(编 号：22-ZJZX-04)，主持人：毕智丽；2. 山东 省重点教学改革项目《高职学前教育专业 “名 园引领、标准共定、资源共享” 院园协同育人 的探究与实践》(编号 2019019), 主持人: 李 燕。

\section{References}

[1] Huang, P. (2020) Curriculum resource construction of dance major in colleges and universities under the concept of curriculum thought and politics. Times of Fortune, 11:54-55.

[2] Ding, S.W. (2020) Research on the practice of college dance quality education from the perspective of curriculum ideology and politics. Journal of Jiangsu Institute of Commerce, 02:82-84.

[3] Hou, C., Liu, J. (2020) Research on the role of red dance in the construction of ideological and political education in colleges and universities. Art Education, 10:223-226.

[4] Lu, F.X. (2020) Practical research on the integration of "Ideological and political" elements into the dance curriculum of Preschool Education Specialty. Science \& Technology Information, 18(14):183-184.

[5] Zhou, J. (2019) Shaping the noble soul with dance -- the ideological and political reform model of dance in Colleges and Universities. Regional Governance, 29:182-184. 